\title{
Characteristics of Atmospheric Dustfall and Soil Magnetic Susceptibility and Environmental Significance in Xining City
}

\author{
Qiang Peng ${ }^{1,2}$, Yongjuan Sun ${ }^{1,2,3^{*}}$ \\ ${ }^{1}$ Qinghai Provincial Key Laboratory of Physical Geography and Environmental Processes, School of Geographical Science, Qinghai \\ Normal University, Xining, P.R. China \\ ${ }^{2}$ MOE Key Laboratory of Tibetan Plateau Land Surface Processes and Ecological Conservation, Qinghai Normal University, Xining, P.R. \\ China \\ ${ }^{3}$ Academy of Plateau Science and Sustainability, People's Government of Qinghai Province \& Beijing Normal University, Xining, P.R. \\ China
}

\begin{abstract}
Magnetic susceptibility is an important means to quickly and economically monitor the enrichment of surrounding environmental elements. As a regional central city on the Qinghai-Tibet Plateau, the relationship between atmospheric dust magnetic susceptibility and heavy metal content in Xining area is relatively lacking. In this paper, the magnetic susceptibility and geochemical element content of the collected dust samples, loess samples, surface soil samples and soil profile samples obtained through long-term observations are analyzed. The results show that the magnetic susceptibility of the dust-fall samples is the highest, the soil samples are the second, and the loess samples are the lowest; the magnetic susceptibility of the dust-fall samples in Xining City has a significant correlation with the elements $\mathrm{Cd}, \mathrm{Cr}, \mathrm{Ni}, \mathrm{Cu}, \mathrm{Pb}, \mathrm{Zn}$ and $\mathrm{Hg}$, and the magnetic susceptibility can be used as an indicator of heavy metal in the soil; the elements $\mathrm{Cr}, \mathrm{Ni}$, $\mathrm{Cu}, \mathrm{Zn}$ and $\mathrm{As}$ in the soil profile are enriched at $20 \mathrm{~cm}$ or $30 \mathrm{~cm}$, which is related to the leaching of surface elements.
\end{abstract}

\section{Introduction}

Environmental magnetism, developed in the 1980s, was a borderline science between environmental science, earth science and magnetism ${ }^{[1-2]}$. It is widely used in soil science and environmental research, and has the characteristics of simple, fast, low-cost, and nondestructive ${ }^{[3]}$. Magnetic susceptibility is a physical concept that refers to the ability of a substance to magnetize under the action of an external magnetic field ${ }^{[4]}$. One of the current research directions of environmental magnetism is to combine magnetic susceptibility with geochemical elements to explore the changes of the environment. Chen et al. ${ }^{[5]}$ found that the magnetic susceptibility characteristics of roadside soil in Xi'an are significantly positively correlated with geochemical elements, Xiao ${ }^{[6]}$ found that the magnetic susceptibility of soil in Fuzhou is correlated with the content of heavy metal elements. Jiang et al. ${ }^{[4]}$ found that the magnetic susceptibility value of the soil profile and the content of heavy metal elements are generally decreasing downward from the surface. The current research on urban atmospheric dust fall focuses on the physical and chemical properties and heavy metal pollution. Yang et al. ${ }^{[7]}$ used factor analysis to study the pollution sources of atmospheric dust in Lanzhou, and the results showed that the main source of atmospheric dust in Lanzhou was coal. Feng et al. ${ }^{[8]}$ found that the method of using magnetic susceptibility can effectively monitor urban pollution in Lanzhou. However, there are relatively few studies that combine urban atmospheric dust with loess and soil to analyze the relationship between magnetic susceptibility and geochemical elements. Cui et al. ${ }^{[9]}$ studied the levels of heavy metals in atmospheric dustfall in Shijiazhuang City and found that the main sources of heavy metal elements in dustfall are coal burning activities, road traffic, industrial and mining enterprise exhaust emissions and soil particulate matter. The heavy metal content in highvalue areas of atmospheric dustfall is consistent with the distribution of industrial areas. Zhao et al. [10] used correlation analysis and principal component analysis methods to analyze the atmospheric dustfall samples collected in Jinan city in order to find out the content characteristics and pollution sources of the elements in the near-surface atmospheric dustfall in Jinan City. It is found that the elements $\mathrm{Cd}, \mathrm{Pb}, \mathrm{Zn}$, and $\mathrm{Se}$ in the atmospheric dust may come from burning coal, the elements $\mathrm{Cr}$ and $\mathrm{Ni}$ come from soil dust, the elements $\mathrm{CaO}$ and $\mathrm{As}$ come from building dust, the element $\mathrm{F}$ mainly comes from automobile exhaust emissions, and $\mathrm{Hg}$ is affected by the factors such as combustion, coal, smelting and transportation.

Xining is a regional center city on the Qinghai-Tibet Plateau, with high population density, fragile ecological environment, and strong aeolian activities in the surrounding area. The average annual atmospheric dust flux is up to $\sim 400 \mathrm{mg} / \mathrm{m}^{2}{ }^{[11]}$. There is abundant 
environmental information in atmospheric dust, but the interpretation of atmospheric dustfall environmental information in Xining is relatively lack, especially the relationship between magnetic susceptibility and geochemical element content. This article compares and analyzes the magnetic susceptibility and element characteristics of atmospheric dust, loess and soil in Xining City, and discusses the environmental significance indicated by the magnetic susceptibility, so as to provide a valuable reference for the interpretation of the atmospheric environment.

\section{Materials and Methods}

\subsection{Sample collection}

The atmospheric dust-full samples were collected from November 2013 to November 2015. A sampling site was set up on the top of the Science and Technology Building on the Chengxi Campus of Qinghai Normal University, Xining City. A total of 8 atmospheric dust samples were collected, divided into winter and dustfull (KJL-D) and summer dustfull (KJL-X). A sampling site was set up in Duoba Town, Huangzhong County, Xining City, and 7 samples were collected, which were divided into winter dustfull (DB-D) and summer dustfull (DB-X). The sampler is a high-neck glass cylinder with a diameter of $20 \mathrm{~cm}$ and a height of $40 \mathrm{~cm}$.

Four loess samples (MFJ-1, MFJ-2, MFJ-3, MFJ-4) were collected at intervals of $5 \mathrm{~cm}$ from a section with a height of $20 \mathrm{~cm}$ in Beishan, Xining City. Three soil samples (XQDJ-1, XQDJ-2, XQDJ-3) were collected at the surface $5 \mathrm{~cm}$ on the roadside of Xiaoqiao Street, Xining City. Two soil samples (QHSD-1, QHSD-2, respectively) were collected at the surface $5 \mathrm{~cm}$ and two soil profiles with a total of 11 soil samples (KJLT1-1, KJLT1-2, KJLT1-3, KJLT1-4, KJLT1-5, KJLT1-6, KJLT2-1, KJLT2-2, KJLT2-4, KJLT2-5, KJLT2-6) were collected in the Chengxi campus of Qinghai Normal University. A total of 24 samples were collected.

\subsection{Sample analysis}

The collected samples were placed in a ventilated and dark place to dry naturally.

The magnetic susceptibility index was measured with the magnetic susceptibility meter (MS2, UK) in the particle size analysis room of Qinghai Province Key Laboratory of Natural Geography and Environmental Processes. The instrument can measure the low-frequency magnetic susceptibility $(470 \mathrm{~Hz})$ and the high-frequency magnetic susceptibility $(4700 \mathrm{~Hz})$ of the sediment, using a $2 \times 2 \times 28 \mathrm{~cm}^{3}$ magnetic special plastic box. The specific processes are as follows:

(1) The natural air-dried samples, filtered through a 20mesh sample sieve in order to remove the gravel, plant roots and other biological residues, were mixed evenly, and then closely put it in the plastic box of known weight. The weight of the sample can be obtained by weighing the box;

(2) In order to minimize the interference of the external environment, it is necessary to stay away from magnetic materials when using the magnetic susceptibility instrument. We adjust the instrument to the low-frequency gear and start the measurement until the instrument is stable. We measure the background value before testing the samples;

(3) The low-frequency mass magnetic susceptibility and high-frequency mass magnetic susceptibility were calculated.

The element indicators were determined in the Xi'an Geological Survey Center, and the pre-processing work is carried out in the pre-processing branch of the Qinghai Provincial Key Laboratory of Natural Geography and Environmental Processes, Qinghai Normal University. The specific steps are as follows:

The natural air-dried samples were passed through a 20-mesh sample sieve, and then mixed thoroughly and grind to below 200 mesh with a ball mill, and 10-20 g of the mixed sample was sealed in a airtight bag and made a mark, and then sent it to the Xi'an Geological Survey Center for testing. Among them, the instrument used to measure the elements $\mathrm{As}$ and $\mathrm{Hg}$ is the AFS-2202E atomic fluorescence spectrometer of Beijing Haiguang Instrument Co., Ltd., and the standard is "DZ/T 02792016"; the instrument used to measure the elements $\mathrm{Cd}$.

$\mathrm{Cr} 、 \mathrm{Ni}, \mathrm{Cu} 、 \mathrm{~Pb}$ and $\mathrm{Zn}$ is the iCAP RQ inductively coupled plasma mass spectrometer of American Thermoelectric Company, and the standard is "GB/T14506.30-2010".

\section{Results and Discussion}

\subsection{Magnetic susceptibility analysis}

The magnetic susceptibility is an index that reflects the degree of difficulty of magnetization of a material, and it is numerically expressed as the ratio of magnetization to magnetic field strength ${ }^{[4]}$. From Table 1, we find that the magnetic susceptibility of dust-fall samples is the highest, followed by soil, and loess is the lowest, and the lowfrequency magnetic susceptibility ( $\chi \mathrm{lf}$ ) of the three are slightly higher than the high-frequency magnetic susceptibility ( $\chi \mathrm{hf}$ ) (Table 1$)$. Generally, the value of $\chi \mathrm{hf}$ is higher than that of $\chi \mathrm{lf}$, but as the frequency of the magnetic field increases, the relaxation time of ultrafine magnetic minerals will be greater than the magnetic susceptibility test time, and this part of the particles will be locked and no longer contributes to the magnetic susceptibility, so its low-frequency magnetic susceptibility is greater than the high-frequency magnetic susceptibility ${ }^{[12]}$.

Because of the same variation trend of low-frequency magnetic susceptibility and high-frequency magnetic susceptibility, the case of low-frequency magnetic susceptibility, referred to as magnetic susceptibility $(\chi)$, was discussed. The value of magnetic susceptibility varies greatly among all the samples. The magnetic susceptibility values of the dustfall samples collected in Xining in winter and summer are the highest, which are $616.27 \times 10^{-8} \mathrm{~m}^{3} \cdot \mathrm{kg}^{-}$ 1 and $504.45 \times 10^{-8} \mathrm{~m}^{3} \cdot \mathrm{kg}^{-1}$, respectively. The magnetic susceptibility values of the loess samples collected in 
Beishan, Xining are the lowest, which are $32.67 \times 10^{-}$ ${ }^{8} \mathrm{~m}^{3} \cdot \mathrm{kg}^{-1}$ and $34.73 \times 10^{-8} \mathrm{~m}^{3} \cdot \mathrm{kg}^{-1}$, respectively. There are many factors that affect the magnetic susceptibility of the soil. Current studies have found that the increase in the magnetic susceptibility of the soil is related to the accumulation of organic matter, excessive use of pesticides and fertilizers, industrial pollution, and the discharge of domestic garbage ${ }^{[12-14]}$.

Table1 Average value of high-frequency magnetic susceptibility and low-frequency magnetic susceptibility of dust, loess and soil

\begin{tabular}{ccc}
\hline sample name & $\chi \mathrm{hf}\left(10^{-8} \mathrm{~m}^{3} \cdot \mathrm{kg}^{-1}\right)$ & $\chi \mathrm{lf}\left(10^{-8} \mathrm{~m}^{3} \cdot \mathrm{kg}^{-1}\right)$ \\
\hline dust & 330.66 & 336.10 \\
loess & 37.71 & 41.00 \\
soil & 115.97 & 121.99 \\
\hline
\end{tabular}

\subsection{Correlation analysis between magnetic susceptibility and geochemical elements}

In order to understand the correlation between magnetic susceptibility and geochemical elements, the correlation analysis between magnetic susceptibility and elements $\mathrm{Cd}$, $\mathrm{Cr}, \mathrm{Ni}, \mathrm{Cu}, \mathrm{Pb}, \mathrm{Zn}, \mathrm{As}, \mathrm{Hg}$ on 24 samples was carried out (Table 2). The results show that the magnetic susceptibility is positive correlation with the elements $\mathrm{Cd}$, $\mathrm{Cr}, \mathrm{Ni}, \mathrm{Cu}, \mathrm{Pb}$, and $\mathrm{Zn}$, and the correlation coefficients are $0.821,0.860,0.872,0.905,0.870,0.778$ respectively, which are significantly correlated within the $99 \%$ confidence interval; the magnetic susceptibility is positive for the element $\mathrm{Hg}$ Correlation, and the correlation coefficient is 0.426 , which is significantly correlated within the $95 \%$ confidence interval; the correlation between magnetic susceptibility and As is not obvious. Among them, the dust collection point of Xining City is located in the city, and the intensity of human activities nearby is high. The burning of residential fossil fuels, the emission of waste gas from industrial areas, and the exhaust gas produced by urban vehicles have increased the heavy metal elements, thereby increasing the magnetic susceptibility of dust.

During the analysis of samples of atmospheric dust fall within the urban area of Jinan City, it was found that the heavy metal elements in atmospheric dust may come from fuel combustion, soil dust, construction dust, and automobile exhaust emissions ${ }^{[10]}$. This is consistent with the research in this article.

Table2 Correlation between magnetic susceptibility value and element content

\begin{tabular}{cccc}
\hline $\begin{array}{c}\text { Magnetic } \\
\text { susceptibility } \\
\text { and elements }\end{array}$ & $\begin{array}{c}\text { Correlation } \\
\text { coefficient }\end{array}$ & $\begin{array}{c}\text { Significance } \\
(99 \%)\end{array}$ & $\begin{array}{c}\text { Significance } \\
(95 \%)\end{array}$ \\
\hline $\mathrm{Cd}$ & 0.821 & $\sqrt{ }$ & $\sqrt{ }$ \\
$\mathrm{Cr}$ & 0.860 & $\sqrt{ }$ & $\sqrt{ }$ \\
$\mathrm{Ni}$ & 0.872 & $\sqrt{ }$ & $\sqrt{ }$ \\
$\mathrm{Cu}$ & 0.905 & $\sqrt{ }$ & $\sqrt{ }$ \\
$\mathrm{Pb}$ & 0.870 & $\sqrt{ }$ & $\sqrt{ }$ \\
$\mathrm{Zn}$ & 0.778 & $\sqrt{ }$ & $\sqrt{ }$ \\
$\mathrm{As}$ & 0.390 & \multicolumn{2}{c}{ No correlation } \\
$\mathrm{Hg}$ & 0.426 & $\times$ & $\sqrt{ }$ \\
\hline
\end{tabular}

\subsection{Changes of elements in the soil profile}

According to the analysis of profile 1 and profile 2 (Figure 1 and Figure 2), the mass fraction of element $\mathrm{Cd}$ in 11 soil samples is $0.14-0.76 \mathrm{ug} / \mathrm{g}$, of which in profile 1 from the surface to the $60 \mathrm{~cm}$ below the ground showed an overall downward trend. Only the mass fraction of $\mathrm{Cd}$ at $20 \mathrm{~cm}$ in profile 2 is $0.76 \mathrm{ug} / \mathrm{g}$, which is slightly higher than the national soil environmental quality standard value (0.6 $\mathrm{ug} / \mathrm{g}$ ). It may be because the element $\mathrm{Cd}$ is leached after being enriched on the surface of the soil, and is enriched at a depth of $20 \mathrm{~cm}$. The mass fraction of element $\mathrm{Hg}$ is $0.08-0.35 \mathrm{ug} / \mathrm{g}$, which does not exceed the human health standard of soil $\mathrm{Hg}$ of $1 \mathrm{ug} / \mathrm{g}$, indicating that the pollution of element $\mathrm{Hg}$ in soil in Xining City is less. But the content is higher at $30 \mathrm{~cm}$ in section 1 , and there is an enrichment effect. The mass fraction of element $\mathrm{Pb}$ in the two sections is $22.9-37 \mathrm{ug} / \mathrm{g}$, which is lower than the national soil environmental quality standard $(170 \mathrm{ug} / \mathrm{g})$. The mass fraction of element $\mathrm{Pb}$ at $20 \mathrm{~cm}$ in section 1 is $28 \mathrm{ug} / \mathrm{g}$, which is enriched. Profile 2 shows an overall downward trend from the surface to $60 \mathrm{~cm}$ underground, which is consistent with the change trend of magnetic susceptibility. The mass fractions of elements $\mathrm{Cr}, \mathrm{Ni}, \mathrm{Cu}$ and $\mathrm{Zn}$ are 56.3$105.7 \mathrm{ug} / \mathrm{g}, 31.2-63.6 \mathrm{ug} / \mathrm{g}, 22.5-66.4 \mathrm{ug} / \mathrm{g}$ and 64.8-113.8 $\mathrm{ug} / \mathrm{g}$, respectively. The maximum limit values of the national standard agricultural land soil for these four elements are $250 \mathrm{ug} / \mathrm{g}, 190 \mathrm{ug} / \mathrm{g}, 100 \mathrm{ug} / \mathrm{g}$, and $300 \mathrm{ug} / \mathrm{g}$. The four elements in both profiles are enriched at $20 \mathrm{~cm}$ or $30 \mathrm{~cm}$, but they are all lower than the national standards for agricultural land soils. The mass fraction of element As is $11.9-67.0 \mathrm{ug} / \mathrm{g}$, the national standard (GB15618-2018) maximum limit value of agricultural land soil is $25 \mathrm{ug} / \mathrm{g}$. The mass fraction of profile 1 is highest at $20 \mathrm{~cm}$ and 30 $\mathrm{cm}$, and the mass fraction of As at $20 \mathrm{~cm}$ in profile 2 is $67.0 \mathrm{ug} / \mathrm{g}$, which is slightly higher than the national soil environment quality standard value ${ }^{[15-17]}$.

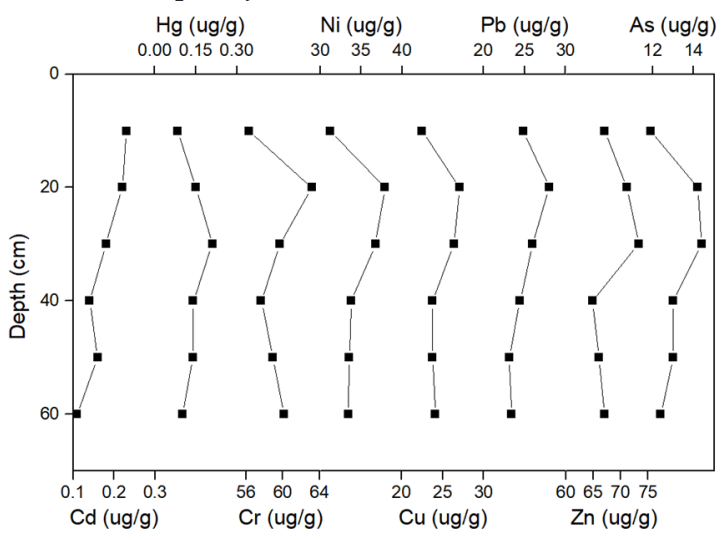

Figure1 Distribution of heavy metal elements in profile 1 


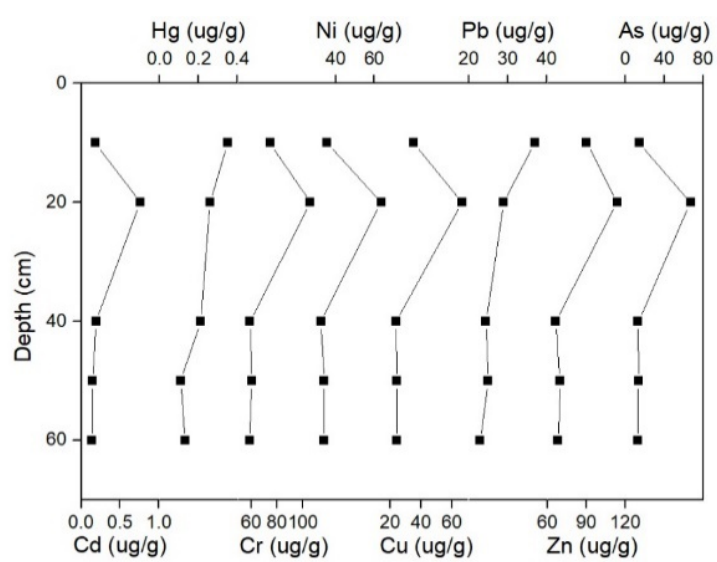

Figure2 Distribution of heavy metal elements profile 2

\section{Conclusions}

The distribution and influencing factors of the magnetic susceptibility and the content of heavy metal elements in atmospheric dustfall, loess and soil in Xining City, and the correlation analysis between the magnetic susceptibility and the content of heavy metal elements in soil profile was discussed in this study, the following conclusions are obtained:

The magnetic susceptibility of the samples in the study area has a significant correlation with the elements $\mathrm{Cd}, \mathrm{Cr}$, $\mathrm{Ni}, \mathrm{Cu}, \mathrm{Pb}, \mathrm{Zn}$, and $\mathrm{Hg}$. The magnetic susceptibility is a convenient indicator of the content of heavy metals.

The heavy metal elements $\mathrm{Cr}, \mathrm{Ni}, \mathrm{Cu}, \mathrm{Zn}$ and $\mathrm{As}$ in the soil are enriched at $20 \mathrm{~cm}$ or $30 \mathrm{~cm}$, which is the result of leaching of surface elements.

\section{Acknowledgments}

This article is one of the phased achievements of the National Natural Science Foundation of China " Reconstruction of flood intensity frequency in Hehuang Valley in $10,000,1,000$, and 100 years and early warning under climate warming " (2021-ZJ-749)

\section{References}

1. Oldfield Frank.(1991) Environmental magnetism-A personal perspective[J]. Oldfield Frank, 10(1).

2. Pan Y.X., Zhu R.X. (1996) Status and progress of environmental magnetism research $[\mathrm{J}]$. Progress in Geophysics, (04): 87-99.

3. Jiang Y.H., Yin H.F., Wang R.H. (2004) Theories, methods and research progress of environmental magnetism [J]. Acta Geosciences, (03): 357-362.

4. Jiang Y.H., Yin H.F., Wang R.H., Kang X.J. (2005) Study on the distribution of soil magnetic susceptibility and heavy metal elements and their correlation in Huzhou City[J]. Journal of Jilin University (Earth Science Edition), (05): 653-660.

5. Chen J.H., Lu X.W. (2011) The characteristics of roadside soil magnetic susceptibility in $\mathrm{Xi}^{\prime}$ an and its environmental significance[J]. Journal of Shaanxi Normal University (Natural Science Edition), 39(05):
76-82.

6. Xiao L. (2018) The characteristics of surface soil magnetic susceptibility and the magnetic response of heavy metal pollution in Fuzhou City[D]. Fujian Normal University.

7. Yang L.P., Chen F.H. (2002) Research on the source of atmospheric dustfall pollutants in Lanzhou City[J]. Acta Scientiae Circumstantiae, (04):499-502.

8. Feng H. (2012) Research on the magnetic characteristics of atmospheric dustfall in Lanzhou City[D]. Lanzhou University.

9. Cui X.T., Luan W.L., Li S.M., Song Z.F. (2012) Source analysis of heavy metal elements in atmospheric dustfall in Shijiazhuang City[J]. Geology in China, 39(04): 1108-1115.

10. Zhao X.Q., Wang Z.H., Wang C.L., Dai J.R., Liu H.F., Ji S.L. (2016) Geochemical characteristics and pollution evaluation of dustfall elements in the nearsurface atmosphere in Jinan City[J]. Geophysical and Geochemical Exploration, 40(01): 154-159

11. E C.Y., Xi Y.S., Sun Y.J., Zhao Y.J., Yang L., Lv S.C. (2016) Analysis of dust flux and particle size characteristics in the northeastern part of the Qinghai-Tibet Plateau[J]. Salt Lake Research, 24(02): 62-67.

12. Deng C.L., Yuan B.Y., Hu S.Y., Liu D.S., Kenneth L.V., Han J.M., Guo Z.T., Lu H.Y. (2000) A review of some research advances in environmental magnetism[J]. Marine Geology and Quaternary Geology, (02):93- 101.

13. Yi Y.L., Gu W.W., Zhang D.G., Li J. (2008) Study on the distribution of soil magnetic susceptibility and heavy metal elements and their correlation in Huludao City[J]. Soil, (05):806-811.

14. Li X.Q., Hu X.F., Sun W.M., Zhang G.L. (2006) Research on Magnetic Monitoring of Urban Soil Pollution[J]. Soil, (01): 66-74.

15. Soil environmental quality agricultural land soil pollution risk management and control standards (excerpts) [J]. Humic Acid, 2018(04): 58-61.

16. Liu Z. (1998) Soil trace elements in China[J]. Advances in Earth Science.

17. Zhou A.G., Cai H.S. (1998) The theory and application of geological environmental quality evaluation[M]. China University of Geosciences Press. 